GEFAD / GUJGEF41(2): 885-910(2021)

\title{
Tasarım Odaklı Düşünme Yaklaşımı Aracılığıyla Sosyal Bilgiler Dersine Yönelik Geliştirilen Ürünlerin Etkililiği*
}

\section{The Effectiveness of Products Developed for the Social Studies Course Through the Design Thinking Approach}

\author{
Arcan AYDEMİR ${ }^{1}$, Turhan ÇETIN ${ }^{2}$ \\ ${ }^{1}$ Artvin Çoruh Üniversitesi, Ĕ̆itim Fakültesi, Türkçe ve Sosyal Bilimler Eğitimi \\ Bölümü, Sosyal Bilgiler Eğitimi Anabilim Dalı.arcan.aydemir@hotmail.com, \\ ${ }^{2}$ Gazi Üniversitesi, Gazi Eğitim Fakültesi, Türkçe ve Sosyal Bilimler Eğitimi Bölümü, \\ Sosyal Bilgiler Eğitimi Anabilim Dall. cetin.turhan@gmail.com
}

\section{$\ddot{O} Z$}

Ürün geliştirmede sıkça kullanılan tasarım odaklı düşünme yaklaşımı özellikle eğitim-öğretim ortamlarında sorun veya eksikliklerin belirlenmesi ve giderilmesinde çok önemlidir. Tasarım odaklı düşünme gibi güncel yaklaşımların bu süreçlerde kullanılması ise yenilikçi çözümlerin ortaya çıkmasına olanak tanıyacaktır. Tasarım odaklı düşünme sürecinde geliştirilen ürünlerin etkililiğine odaklanan bu çalışmada ise deneysel süreçte kullanılan ürünlerin akademik başarlya etkisi ve sürece yönelik ögrrenci görüşlerinin ortaya çıkarılması amaçlanmıştır. Araştırmada karma araştırma desenlerinden sıralı açıklayıcı desen kullanılmıştır. Araştırmanın nicel boyutunda deneykontrol gruplu yarı deneysel desen, nitel boyutunda ise olgubilim (fenomenoloji) kullanılmıştır. Araştırmanın çalışma grubunu ortaokul 6.sınıfta öğrenim gören öğrenciler oluşturmaktadır. Araştırmada elde edilen verilerin toplanmasında "Elektronik Yüzyıl" başarı testi ve yarı yapılandırılmış görüşme formu kullanılmıştır. Araştırmada elde edilen nitel veriler içerik analizi,

\footnotetext{
* Alıntılama: Aydemir, A. ve Çetin, T. (2021). Tasarım odaklı düşünme yaklaşımı aracılığıyla sosyal bilgiler dersine yönelik geliştirilen ürünlerin etkililiği Gazi Üniversitesi Gazi Ĕgitim Fakültesi Dergisi, 41(2), 885-910.

** Bu çalışma birinci yazarın ikinci yazar danışmanlığında tamamladığı "Sosyal Bilgilerde Tasarım Odaklı Düşünme Yaklaşımı” adlı doktora tezinden üretilmiştir.
} 
nicel veriler ise Mann Whitney u ile Wilcoxon Işsaretli Stralar testleri kullanılarak analiz edilmiştir. Araştırma sonucunda tasarım odakl düşünme aracılığıyla tasarlanan ürünlerle gerçekleştirilen süreç sonucunda elde edilen puanların, programın ön gördüğü şekilde gerçekleştirilen süreç sonunda elde edilen puanlara göre istatistiki olarak anlamlı bir şsekilde farklılaştığına ulaşılmıştır. Başka bir ifadeyle deneysel süreçte kullanılan ürünler akademik başarıyı olumlu yönde etkilemişstir. Buna ek olarak deneysel işlemin uygulandığı öğrenci grubu ise süreci, kolay öğrenme sağlaması, derste oyunların kullanılması, dersin eğlenceli hale gelmesi şeklinde değerlendirmişlerdir.

Anahtar Sözcükler: Inovasyon, Tasarım odaklı düşünme, Sosyal bilgiler

\section{ABSTRACT}

The design thinking approach, commonly used in product development, is important in identifying and eliminating problems or deficiencies, especially in educational settings. Using contemporary approaches such as design thinking in these processes will enable innovative solutions to emerge. In this study, which focuses on the effectiveness of the products developed in the design thinking process, it is aimed to reveal the effect of the products used in the experimental process on the academic achievement and students' views on the process. Sequential explanatory design, one of the mixed research designs, was used in the study. The study used a quasi-experimental and control groups design in the quantitative phase and phenomenology in the qualitative phase. The sample consisted of middle school sixth-grade students. The data were collected using the "Electronic Century" Achievement Test and a semi-structured interview form. The qualitative data were analysed using content analysis and the quantitative data were analysed using the Mann-Whitney $U$ test and the Wilcoxon signed-rank test. The analysis results showed a statistically significant difference between the scores obtained at the end of the design thinking-based product development process and the scores obtained at the end of the curriculum-based process. In other words, the products used in the experimental process positively affected the academic achievement. In addition, the experimental group held the view that the design thinking-based product development process facilitated learning, involved games and made the course fun.

Keywords: Innovation, Design thinking, Social studies

\section{GİRIS}

Eğitim-öğretim ortamlarında yaşanan birçok ihtiyaç ve sorunun belirlenmesinde öğretmen ve yöneticilere önemli görevler düşmektedir. Özellikle program, öğretmen, öğrenci ve finansman kaynaklı sorunlar eğitim-öğretim faaliyetlerini yakından etkilemektedir. Bu faaliyetler sırasında karşılaşabilecek sorun veya ihtiyaçların temelinde yatan sebeplerin ortaya çıkarılması ve etkili çözümler üretilmesinde ise hedef kitleye odaklanan süreçlerin bilinmesi ve uygulanmasına ihtiyaç duyulmaktadır. 
Eğitim-öğretim faaliyetlerinin temel işlevlerini yerine getirebilmesi için eğitim sistemindeki sorun ve eksiklikler ortadan kaldırılmalıdır (Sarıbaş ve Babadağ, 2015, s.19). Eğitim-öğretim ortamlarında yaşanan sorun veya ihtiyaçları gidermede etkili yollar bulmak gerekir. Değişen ve gelişen dünyada ortaya atılan bu yolların mümkün olduğunca inovatif (yenilikçi) olması, gelişime ayak uydurmak ve yeni neslin sürece daha kolay adapte olmasını sağlamak açısından önemlidir. Bu durum ise hayatın her alanında olduğu gibi eğitim alanın da inovasyonun sürece dâhil edilmesini gerekli kılmıştır.

İnovasyon bilinen teknolojilerin yeni alanlarda nasıl kullanılacağına veya tam tersi olarak kalıcı alanlarda kullanılmak üzere yeni teknolojilerin nasıl geliştirilmesi gerektiğine odaklanmaktadır (Carlgren, 2013, s.4). Bir süreci ifade eden inovasyon farklı alanlarda çeşitli aşamalardan oluşmaktadır. İnovasyon süreçleri birçok alanda çözüm ve problemlerin ortaya çıkarılması veya seçilmesinde kullanılmaktadır. Beckman ve Barry (2007) inovasyon sürecini çözümlerin ve problemlerin ortaya çıkarılması ve seçilmesi olarak ele almışlardır. Sistem, zorunluluklar, çözüm yolları ve gözlemler gibi kavramları içeren bu sürece Şekil 1'de yer verilmiştir.

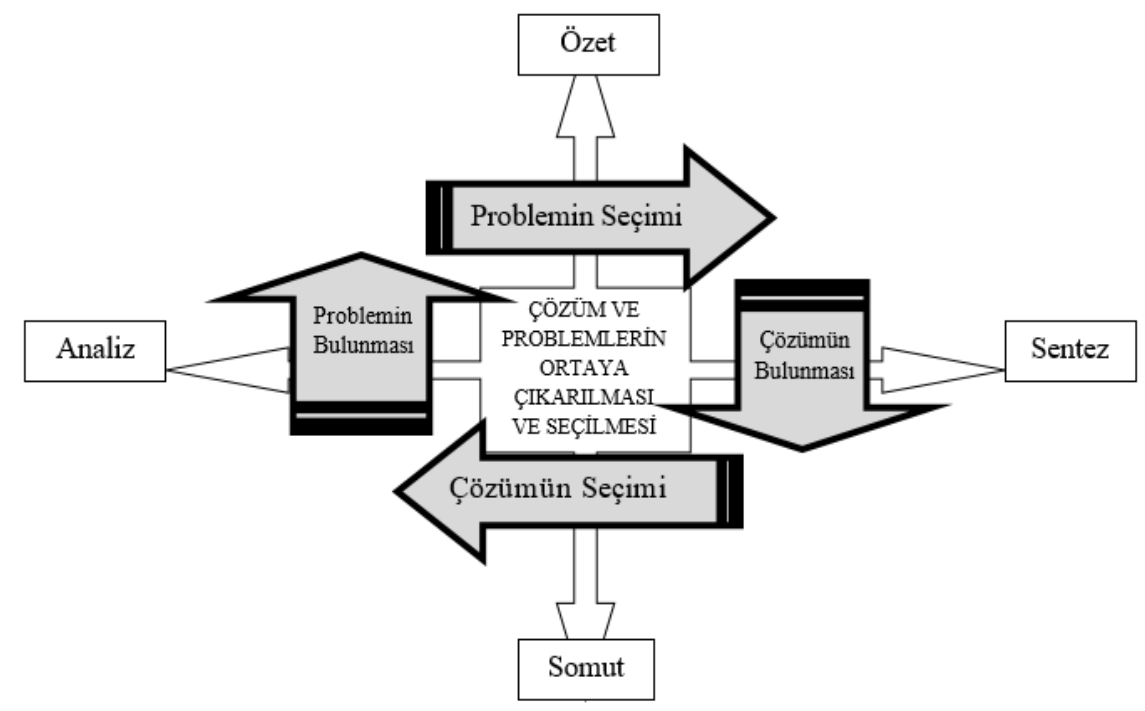

Şekil 1. Çözüm ve Problemlerin Ortaya Çıkarılması ve Seçilmesi Olarak İnovasyon Süreci, Beckman ve Barry, 2007, s.44 
Her alanda oluşturulacak yeniliklerin yukarıda ifade edilen birtakım adım ve içeriklere uygun olarak gerçekleştirilmesi ise özellikle probleme odaklanılan durumlarda hem problemin ortaya çıkarılması hem de çözüm yollarının ifade edilmesi açısından önemlidir. İnovasyon ve inovasyon süreçlerinin kullanılması gereken alanlardan birisi de eğitim-öğretimdir. Eğitim-öğretim faaliyetlerine yönelik yeni ürünler geliştirmek, yeni süreçler tasarlamak; eğitimi hedefe ulaştırmak ve 21. yüzyıl becerilerine katkıda bulunmak açısından önemlidir. Eğitimde inovasyonu sağlamak, bazı sorun ve eksiklikleri tespit edip, bunlara yenilikçi çözüm önerileri sunmak için yeni yaklaşımlar kullanmak gerekir. Bu yaklaşımlardan biri de tasarım odaklı düşünme yaklaşımıdır. Tasarım odaklı düşünme 2000'li yılların başında inovasyon kapsamında bir yaklaşım olarak ortaya çıkmıştır. İnovasyon temelli sektörlerde birkaç yıl içinde yayılım göstererek, özellikle işlerini dönüştürmeyi hedefleyen yöneticiler ile daha nitelikli öğrenciler yetiştirmeyi hedefleyen işletme okullarında tasarım odaklı düşünmeye ilgi artmıştır (Carlgren, 2013, s.3).

Tasarım odaklı düşünme geleneksel stratejilere yeni fikir ve kavramlar düzeyinde inovasyona yönlendirmeye yardımcı olan bir alan olarak birçok alanda üne sahip olmuştur (Knight, Fitton, Phillips ve Price, 2019, s.1931). Tasarım odaklı düşünme, tasarımcılar tarafından oluşturulan ürünlerin, yapılarını, hizmetlerini, alanını ve karmaşık sistemlerini birleştiren bir tasarım yöntemi olarak ifade edilebilir ( $\mathrm{Li}$, Qian, Chen ve Zhang, 2019, s.101). Tasarım odaklı düşünme genellikle tasarımcılar tarafından uygulansa da son zamanlarda farklı alanlardan (işletme eğitimi, eğitim bilimleri...) birçok kişi tarafından kullanılmaya başlanmıştır.

Tasarım odaklı düşünme, ürün tasarımını geliştirmek için ortaya atılan stratejileri kapsamaktadır (Chin, Blair, Wolf, Conlin, Cutumisu, Pfaffman ve Schwartz, 2019, s.340). Tasarım odaklı düşünme için başarısızlık, kaliteli ürün elde etmenin verimli yollarından biridir (Araújo, Anjos ve Silva, 2015, s.84). Tasarım odaklı düşünmenin benimsenmesine engel olan ve endişe edilen en önemli konu başarısızlıktır (Brown ve Wyatt, 2010, s.35). Özellikle geliştirilen ürünlerin test edilmesinde karşılaşılan 
başarısızlıklar, ürünlerin kalitesini arttırarak, amaca daha fazla hizmet eden ürünlerin oluşturulmasına katkıda bulunacaktır.

Tasarım odaklı düşünme felsefesi temelde çelişki, empati ve rahatlamış bir bakış açısını gerektirmektedir (Ballie, 2019, s.984). Buna ek olarak beceriye odaklanan tasarım odaklı düşünme süreci, katılımcıların bu becerileri kendilerinde fark etmelerine ve geliştirmelerine de katkı sağlayabilir. Literatür incelendiğinde çeşitli eğitim-öğretim kurumlarınca (Stanford Üniversitesi, Rotman ve Darden İşletme Okulu, Hasso Plattner Enstitüsü), tasarım şirketlerince (IDEO) ve birtakım çalışmalarda (Araújo ve diğerleri, 2015; Brown ve Wyatt, 2010; Dunne ve Martin, 2006; Gibbons, 2016; Ingle, 2013; Kendir-Çopurlar ve Kılıç-Öztürk, 2015; Meinel ve Leifer, 2010; Morris ve Warman, 2015; Thoring ve Müller, 2011) tasarım odaklı düşünme sürecine yönelik pek çok sınıflandırmanın yapıldığı görülmektedir. Bütün bu sınıflamalardan yola çıkarak tasarım odaklı düşünme yaklaşımı empati-keşif, yorumlama/tanımlama, fikir üretme, prototip ve test olmak üzere toplamda 5 adımda uygulanabilecek bir yaklaşım olarak ifade edilebilir. Sosyal bilgiler dersi hem öğretmen hem de öğrenci açısından tasarım süreçlerini bünyesinde barındıran bir derstir. Sosyal bilgiler dersine yönelik öğrenci ve öğretmenler tarafından hazırlanan ve uygulanan tasarım etkinlikleri eğitim-öğretim ortamlarının zenginleştirilmesi açısından önemlidir (Çetin ve Aydemir, 2018, s.452). Aynı zamanda bir tasarım etkinliği süreci olan tasarım odaklı düşünme yaklaşımı da sosyal bilgiler dersi kapsamında tasarım etkinlikleri geliştirilirken önemli bir yol olarak kullanılabilir.

Eğitim-öğretim sürecine yönelik ürün geliştirmeye odaklanan birçok çalışma vardır. Ancak tasarım odaklı düşünme yaklaşımı gibi inovasyona odaklanan çeşitli yeni yaklaşımlar kullanılarak ürün geliştirme çalışma örnekleri yetersizdir. Türkiye'deki milli eğitim sisteminin de hedeflerine dâhil ettiği inovasyonu geliştirmek için farklı yaklaşımlara ihtiyaç vardır. Bu bağlamda Millî Eğitim Bakanlığı da eğitimde inovasyon için tasarım odaklı düşünmeye önem vermekte ve hizmet içi eğitimlerle bu yaklaşımın kullanımının arttırılmasını hedeflemektedir. (TRT Haber, 2019). Türkiye'de son yıllarda eğitim-öğretim alanında tasarım odaklı düşünmeye odaklanan bir takım çalışmalar (Altun, 2019; Atacan, 2020; Girgin, 2019; Girgin, 2020; Kayalı, 2019; Öztürk, 2020; 
Şahin, 2019) yapılmış olsa da, yaklaşımın daha iyi anlaşılması için daha fazla uygulama örneklerini içeren çalışmalara ihtiyaç vardır.

\section{Araştırmanın Amacı}

Araştırmanın temel amacı tasarım odaklı düşünme yaklaşımı aracılığıyla oluşturulan ürünlerin etkililiğini belirlemektir. $\mathrm{Bu}$ temel amaç doğrultusunda katılımcıların hem akademik başarıları hem de sürece yönelik görüşleri incelenmiştir. Araştırmanın temel amacı doğrultusunda ise aşağıdaki sorulara yanıt aranmıştır:

*Deney ve kontrol grubunun ön test puanları arasında istatistiki olarak anlamlı farklılık var midır?

*Deney ve kontrol grubunun son test puanları arasında istatistiki olarak anlamlı farklılık var midir?

*Deney grubunun ön test ve son test puanları arasında istatistiki olarak anlamlı bir fark midir?

*Kontrol grubunun ön test ve son test puanları arasında istatistiki olarak anlamlı bir farklılık var midır?

*Deney grubunda yer alan katılımcıların sürece yönelik görüşleri nelerdir?

\section{YÖNTEM}

\section{Araştırmanın Modeli}

Çalışmada karma araştırma desenlerinden sıralı açıklayıcı (NICEL $\rightarrow$ nitel) desen kullanılmıştır. Bu desenin temel amacı öncelikle nicel yöntemleri kullanarak, nicel sonuçlar elde etmek ve bu sonuçlara yönelik daha derinlemesine açılama getirmek için nitel yöntemler kullanmaktır (Creswell, 2017, s.6). Bu bağlamda öncelikle nicel yöntem uygulanmış ve nicel veriler toplanmış, sonrasında nitel veriler toplanmıştır. Araştırmanın nicel boyutunda deney-kontrol gruplu yarı deneysel desen, nitel boyutunda ise olgubilim (fenomenoloji) kullanılmıştır. Araştırma kapsamında ürünlerin etkisinin daha iyi anlaşılması için "Elektronik Yüzyıll" ünitesine yönelik geliştirilen başarı testinden elde edilen puanlar arasında anlamlı farklılık olmayan iki grup seçilmiştir. Bu bağlamda deney grubuna tasarım odaklı düşünme yaklaşımı aracılığıyla geliştirilen ürünlerle, kontrol 
grubuna ise programın öngördüğü şekilde öğretim gerçekleştirilmiştir. Her iki grubu da süreç öncesi ve sonrasında geliştirilen başarı testi uygulanmıştır. Süreçte her iki gruba da konu öğretimini mevcut sosyal bilgiler öğretmeni gerçekleştirmiştir. Araştırmanın nitel boyutunda ise deney grubunda yer alan ve tesadüfi olarak seçilen toplam 7 öğrenci ile görüşmeler yapılmıştır. Bu sayede öğrencilerin sürece yönelik değerlendirmeleri ortaya çıkarılmıştır. Deney grubunda gerçekleştirilen öğretim sürecindeki ürünler sosyal bilgiler öğretmen adayları ile gerçekleştirilen tasarım odaklı düşünme sürecinde oluşturulmuştur. Şekil 2'de araştırma sürecine yer verilmiştir.

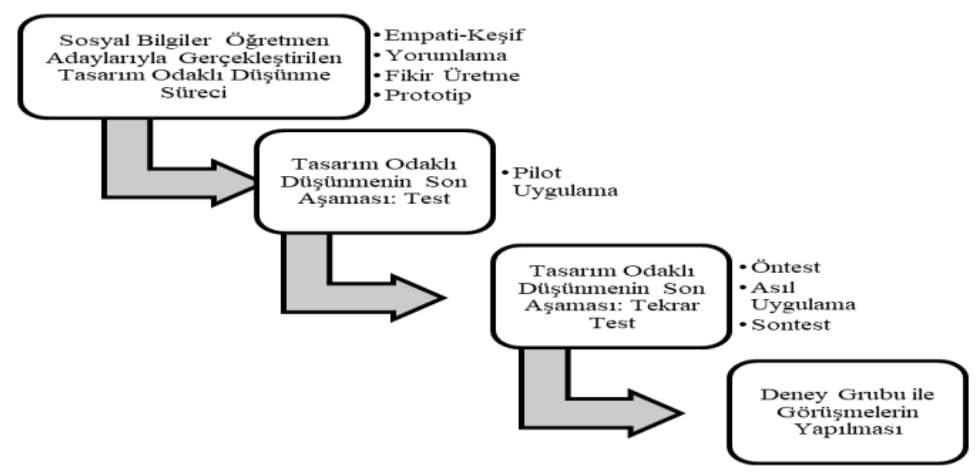

Şekil 2. Araştırmanın Uygulama Süreci

Sosyal bilgiler öğretmen adaylarıyla gerçekleştirilen tasarım odaklı düşünme sürecinde empati-keşif aşamasında sosyal bilgilerde yaşanan sorunlar veya ihtiyaçlar ortaya çıkarılmış, yorumlama aşamasında bu sorunlar sınırlandırılarak temelde 3 sorun-ihtiyaç (Etkinlik ve materyal eksikliği, sözcüklerin anlaşılmaması) belirlenmiştir. Belirlenen bu 3 sorununun çözümüne yönelik fikir üretme aşamasında beyin fırtınası aracılığıyla çözüm önerileri geliştirilmiştir. Prototip aşamasında fikirler somutlaştırılmış ve içlerinden işe yarayabileceğine karar verilen 3 prototip (Öğretmenlere yönelik materyal tasarlama kılavuzu (Öğretmen bu kılavuzu kullanarak kazanımlara yönelik materyaller tasarlamıştır.), etkinlik çarkı (içerisinde Nesi var?, Tersine Çember gibi etkinlik ve oyunları barındıran çark) ve kelime ormanı (sözlük)) süreçte kullanılmış, süreç gözlemlenmiş ve prototiplerde düzenlemeler yapılarak test (asıl uygulama) edilmiştir. Bu çalışmadaki veriler ile çalışma grubu ise asıl uygulama kapsamındadır. Geliştirilen 
ürünlerin içeriği 2005 6.sınıf Sosyal Bilgiler Öğretim Programı'nda (Millî Eğitim Bakanlığı, 2005) yer alan "Elektronik Yüzyıl” ünitesindeki kazanımlar (1.Kazanım: Sosyal bilimlerdeki çallşma ve bulgulardan hareketle sosyal bilimlerin toplum hayatina etkisine örnekler verir, 2.Kazanım: Bilimsel ve teknolojik gelişmelerin gelecekteki yaşam üzerine etkilerine ilişkin yaratıcı fikirler ileri sürer, 3.Kazanım: Tip alanındaki buluş ve gelişmelerle insan hayatı ve toplumsal dayanışma arasındaki iliş̧kiyi fark eder, 4.Kazanım: Telif ve patent haklart sakl ürünlerin yasal yollardan temin edilmesinin gerekliliğini savunur, 5.Kazanım: Uygulama ve eserlerinden yola çıkarak Atatürk'ün akılcılığa ve bilime verdiği önemi fark eder.) dikkate alınarak hazırlanmıştır. Şekil 3'te araştırma kapsamında geliştirilen materyal tasarlama kılavuzu ile kelime ormanı kapak sayfalarına ve etkinlik çarkının görseline yer verilmiştir.

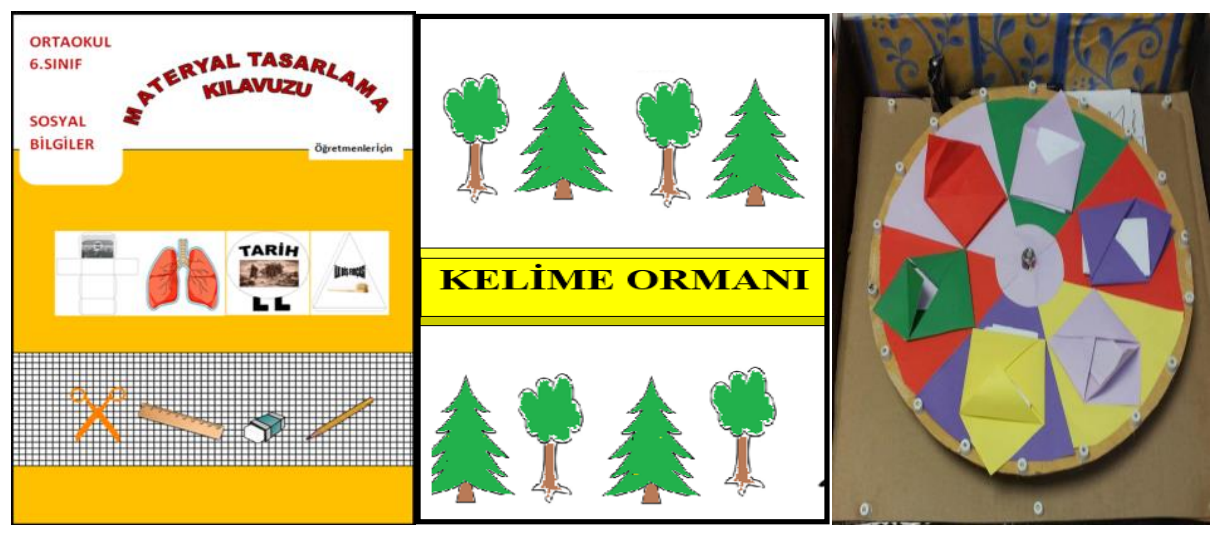

Şekil 3. Geliştirilen Ürünler

Materyal tasarlama kılavuzunu kullanarak öğretmen tarafından geliştirilen ürün örneklerine ise Şekil 4'te yer verilmiştir. 


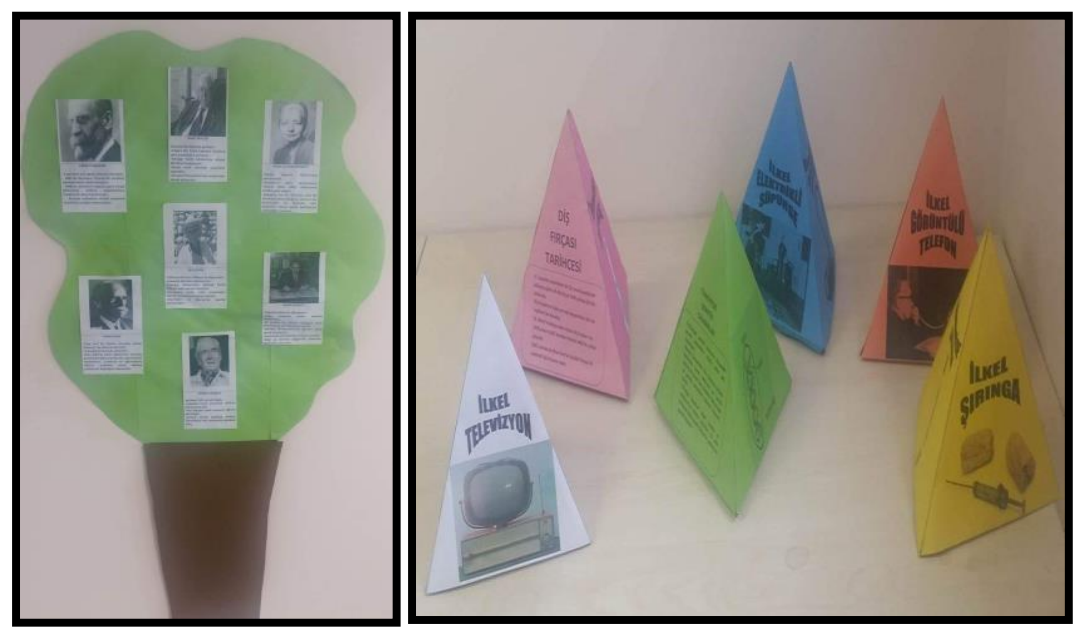

Şekil 4. Materyal Tasarlama Kılavuzu Aracılığıyla Geliştirilen Materyal Örnekleri

\section{Çalışma Grubu}

Araştırmanın çalışma grubunu amaçlı örnekleme yöntemi ile belirlenmiş, Artvin ili merkez ilçede öğrenim gören ortaokul 6.sınıf öğrencileri oluşturmaktadır. Tablo 1'de deneysel süreçte yer alan katılımcılara ait bazı bilgilere yer verilmiştir.

Tablo 1. Deneysel Süreçte Yer Alan Katılımcılara İlişkin Bilgiler

\begin{tabular}{lccc}
\hline Çalışma Grupları & K1z & Erkek & Toplam \\
\hline & $\mathrm{n}$ & $\mathrm{n}$ & $\mathrm{n}$ \\
\cline { 2 - 4 } Deney Grubu & 7 & 12 & 19 \\
Kontrol Grubu & 8 & 10 & 18 \\
\hline Toplam & 15 & 22 & 37 \\
\hline
\end{tabular}

Tablo 1 incelendiğinde 19'u deney 18'i ise kontrol grubunda olmak üzere toplamda 37 öğrencinin çalışma grubunda yer aldığı görülmektedir. Buna ek olarak deney grubunda yer alan 7 öğrenci ile sürece yönelik görüşmeler yapılmıştır. Tablo 2'de ise araştırmanın nitel boyutunda yer alan katılımcılara ilişkin bilgilere yer verilmiştir. 
Tablo 2. Nitel Boyutta Yer Alan Katılımcılara İlişsin Bilgiler

\begin{tabular}{lll}
\hline Grup & Cinsiyet & Kod \\
\hline & Kız & DGÖ-1 \\
Deney Grubu & Kız & DGÖ-2 \\
& Kız & DGÖ-3 \\
& Erkek & DGÖ-4 \\
& Kız & DGÖ-5 \\
& Erkek & DGÖ-6 \\
& Erkek & DGÖ-7 \\
\hline
\end{tabular}

Araştırmanın nitel boyutunda 3'ü erkek olmak üzere toplamda 7 öğrenci yer almıştır. Öğrenci görüşleri deşifre edilirken DGÖ (Deney Grubu Öğrencisi) -1, DGÖ-2 şeklinde kodlanmıştır.

\section{Veri Toplama Araçları}

Araştırmada veri toplama aracı olarak araştırmacı tarafından geliştirilen "Elektronik Yüzyıl” ünitesi başarı testi ve görüşme formu kullanılmıştır.

Deneysel sürecin işe yarayıp yaramadığını belirlemek amacıyla "Elektronik Yüzyıl" ünitesine yönelik başarı testi geliştirilmiştir. Başarı testi geliştirilmeden önce Elektronik Yüzyıl ünitesindeki kazanımlar 2005 6.sınıf Sosyal Bilgiler Öğretim Programı’ndaki şekliyle incelenmiş ve her bir kazanım için birbirlerine yakın sayılarda toplamda 32 madde yazılmıştır. Uzman görüşü (alan uzmanı ve ölçme değerlendirme uzmanı) alınarak başarı testindeki madde sayısı 25'e indirilerek pilot uygulaması gerçekleştirilmiştir. Pilot uygulama sonucunda elde edilen veriler SPSS paket programında analiz edilerek madde ayırt edicilik indeksleri ile güçlük indeksleri incelenmiştir. Analiz sonucunda geliştirilen testte negatif yönlü ayırt edicilik değerine sahip madde saptanmamıştır. Madde ayırt edicilik değeri .30'un altında olan maddeler ise testten çıkarılmıştır. Bu işlem sonucunda ise başarı testi 20 soruya inmiş ve deneysel süreçte öntest ve sontest olarak bu hâli kullanılmıştır.

Araştırmanın nitel boyutunda ise veriler yarı yapılandırılmış görüşme formu aracıllğıyla toplanmıştır. Yarı yapılandırılmış görüşme formunda deney grubunda yer alan 
öğrencilerden tesadüfi olarak seçilenlere “Elektronik Yüzyıl ünitesinde kullanılan ürünler sizin için faydalı oldu mu? Faydalı olduysa ne gibi faydalarının olduğunu açıklayınız." sorusu yöneltilmiş ve deneysel süreci değerlendirmeleri istenmiştir.

\section{Etik Kurallara Uygunluk}

Araştırmanın uygulama aşaması için Artvin Çoruh Üniversitesi Bilimsel Araştırma ve Yayın Etiği Kurulu'ndan etik kurul izni alınmıştır (EK-1). Araştırma kapsamında yer alan katılımcıların kimlik bilgileri herhangi bir yerde paylaşılmamıştır. Elde edilen veriler geçerlilik ve güvenilirlik kuralları gözetilerek analiz edilmiştir. Son olarak çalışma birinci yazarın ikinci yazar danışmanlığında tamamladığı doktora tezinin bir bölümünden üretilmiş, bu durum makalenin başında yer verilen dipnotta belirtilmiştir.

\section{Verilerin Analizi}

Nicel verilerin analizinde deneysel sürecin etkisini belirlemek amaciyla her bir gruptaki kişi sayısının 30 kişiden az olması ve verilerin normal dağılım göstermemesinden dolayı non parametrik testlerden olan Mann Whitney-U ile Wilcoxon İşaretli Sıralar testi kullanılmıştır. SPSS paket programı aracılığıyla analiz edilen verilerde, hem deney hem de kontrol grubunun ayrı ayrı ön ve sontest puanlarının karşılaştırma aşamasında Wilcoxon İşaretli Sıralar testi, deney ve kontrol gruplarının öntestleri ve sontestlerini karşılaştırma aşamasında ise Mann Whitney U testi kullanılmıştır.

Araştırmada nitel verilerin analizinde ise içerik analizi yöntemi kullanılmıştır. Görüşmeler ses kaydı alınarak gerçekleştirilmiştir. Görüşme sonrasında ses kaydı şeklinde kaydedilen veriler deşifre edilmiştir. Deşifrelerden bazı kodlar elde edilmiş ve bu kodlar şekille görselleştirilmiştir.

\section{Geçerlilik ve Güvenirlik}

Geliştirilen başarı testinin güvenirlik çalışmasında Kuder Richardson yöntemi kapsamındaki KR-20 güvenirlik formülü kullanılmıştır. Geliştirilen başarı testinin KR20 güvenirlik katsayısı .72 olarak hesaplanmıştır. Grup çalışmalarında geliştirilen 
testlerin güvenirlik katsayılarının .60 ile .80 arasında olması yeterlidir (Özçelik, 2010). $\mathrm{Bu}$ yüzden geliştirilen başarı testinin güvenilir olduğu söylenebilir.

Araştırma kapsamında elde edilen nitel veriler yazıya dökülerek, sosyal bilgiler eğitimcisi alan uzmanına sunulmuştur. Hem araştırmacılar hem de alan uzmanının veri kodları karşılaştırılarak uyuşum yüzdesi hesaplanmıştır. Uyuşum yüzdesi hesaplanırken "(Uyuşum Miktarı x 100) / (Uyuşum miktarı + Uyuşmazlık miktarı)" formülü (Croll, 1986; Robson, 1993; Bakeman ve Gottman, 1997'den aktaran Türnüklü, 2000) kullanılmıştır. Araştırmacılar arasındaki uyum \%100 olacak şekilde tartışılmış, uyum \%100 olacak şekilde veriler yeniden kodlanmıştır.

\section{BULGULAR ve YORUM}

Araştırma kapsamında "Elektronik Yüzyıl" ünitesine yönelik akademik başarıları arasında anlamlı farklılık olmayan iki gruptan birine (deney grubu) tasarım odaklı düşünme yaklaşımı aracılığıyla elde edilen ürünler ile öğretim gerçekleştirilmiştir. Diğer gruba ise (kontrol grubu) programın öngördüğü şekilde öğretim gerçekleştirilmiş ve katılımcıların öntest ve sontestlerden elde ettikleri puanlar incelenmiştir.

Araştırma öncesinde çalışma grubunda yer alan gruplar arasındaki başarı puanlarında anlamlı farklılık olmaması, uygulanan deneysel yolun etkili olup olmadığını belirlemek için önemlidir. Deneysel sürecin etkisini daha iyi anlamak için "Elektronik Yüzyll" ünitesine yönelik akademik başarıları arasında anlamlı farklılık olmayan iki farklı grup belirlenmiştir. İki grubun bu özelliğini belirlemek amacıyla da ön testten elde edilen başarı puanları Mann-Whitney U testi aracılı̆̆ılyla analiz edilmiştir. Tablo 3 'te deney ve kontrol grubu öntest başarı puanlarının Mann-Whitney U testi sonuçlarına ver verilmiştir.

Tablo 3. Ön Test Sonuçlarının Mann-Whitney U Testi Analiz Bulguları

\begin{tabular}{lccccc}
\hline Grup & $\mathrm{n}$ & Sira Ortalamas1 & Sira Toplamı & $\mathrm{U}$ & $\mathrm{p}$ \\
\hline Deney & 19 & 16.74 & 318.00 & 128.00 & .187 \\
Kontrol & 18 & 21.39 & 385.00 & & \\
\hline
\end{tabular}


Deney ve kontrol gruplarının ön test puanları dikkate alınarak uygulanan Mann-Whitney $\mathrm{U}$ testi analiz bulguları incelendiğinde grupların öntest puanları arasında anlamlı farklılığın olmadığı görülmektedir ( $\mathrm{U}=128.00, \mathrm{p}>.187$ ). Bir başka ifadeyle katılımcıların ön testleri arasındaki farklılık istatistiksel açıdan önemli değildir. Bu bulgu deney ve kontrol gruplarının "Elektronik Yüzyıl” ünitesine yönelik ön bilgileri arasında anlamlı farklılık olmadığını göstermektedir. Her iki grubun da başarı testinden elde ettikleri puanlar arasında istatistiki olarak anlamlı farklılığın olmaması ise araştırmada gerçekleştirilen deneysel sürecin etkililiğini ortaya çıkarmaya katkı sağlaması açısından önemlidir.

Tasarım odaklı düşünme yaklaşımı aracıllı̆ıyla geliştirilen ürünlerin etkililiğini belirlemek amaciyla deney ve kontrol grubunun uygulama sonrasında "Elektronik Yüzyıl” başarı testinden elde ettikleri puanlar Mann-Whitney U testi aracılığıyla analiz edilmiş ve Tablo 4'teki bulgulara ulaşılmıştır.

Tablo 4. Son Test Sonuçlarının Mann-Whitney U Testi Analiz Bulguları

\begin{tabular}{lccccc}
\hline Grup & $\mathrm{n}$ & Sira Ortalamas1 & Sira Toplamı & $\mathrm{U}$ & $\mathrm{p}$ \\
\hline Deney & 19 & 23.08 & 438.50 & 93.50 & $.01^{*}$ \\
Kontrol & 18 & 14.69 & 264.50 & & \\
\hline *p $<.05$ & & & & &
\end{tabular}

Tablo 4 incelendiğinde deney ve kontrol grubunda yer alan katılımcıların sontestten elde ettikleri puanlar arasında istatistiki olarak anlamlı farklılığın olduğu görülmektedir $(\mathrm{U}=93.50, \mathrm{p}<.05$ ). Grupların siralar ortalaması değerleri (Deney Grubu $(\mathrm{sO})=23.08$, Kontrol Grubu $(\mathrm{SO})=14.69$ ) incelendiğinde ise durumun deney grubundaki katılımciların lehine olduğu görülmektedir. Bu durum tasarım odaklı düşünme yaklaşımı aracılığıyla oluşturulan ürünler kapsamındaki etkinlik ve materyallerin kullanımının öğrencilerin "Elektronik Yüzyll" ünitesine ilişkin başarısını arttırmada programın ön gördüğü şekilde gerçekleştirilen öğretimden daha etkili olduğu şeklinde yorumlanabilir.

Oluşturulan her iki grubun da öğretim öncesi ve sonrası üniteye yönelik akademik başarıları karşılaştırılmıştır. Tablo 5'te deney grubundaki katılımcıların deneysel işlem (Tasarım odaklı düşünme aracılığıyla geliştirilen ürünlerle gerçekleştirilen öğretim) 
öntest ve sontestten elde ettikleri puanların Wilcoxon işaretli sıralar testi sonuçlarına yer verilmiştir.

Tablo 5. Deney Grubunda Yer Alan Katılımcılardan Elde Edilen Öntest ve Sontest Başarı Puanlarının Wilcoxon İşaretli Sıralar Testi Sonuçları

\begin{tabular}{lccccc}
\hline $\begin{array}{l}\text { Sontest - } \\
\text { Öntest }\end{array}$ & $\mathrm{n}$ & Sıra Ortalamas1 & Sıra Toplamı & $\mathrm{z}$ & $\mathrm{p}$ \\
\hline Negatif Sıra & 3 & 8.50 & 25.50 & $2,80^{*}$ & $.005^{* *}$ \\
Pozitif Sıra & 16 & 10.28 & 164.50 & & \\
Eşit & 0 & - & - & & \\
\hline
\end{tabular}

*Negatif sıralar temeline dayal1, $* * \mathrm{p}<.05$

Tablo 5 incelendiğinde deneysel işlemin gerçekleştirildiği (Tasarım odaklı düşünme yaklaşımı sonucunda oluşturulan ürünlerle öğretim) grubun deneysel süreç öncesi ve sonrası elde edilen başarı puanları arasında istatistiki olarak anlamlı bir farkın olduğu görülmektedir $(\mathrm{z}=2.80, \mathrm{p}<.05)$.

Tablo 6'da ise kontrol grubunda yer alan katılımclların "Elektronik Yüzyll" ünitesine yönelik geliştirilen başarı testinde elde ettikleri ön ve sontest puanlarının Wilcoxon İşaretleri Sıralar testi sonuçlarına yer verilmiştir.

Tablo 6. Kontrol Grubunda Yer Alan Katılımcilardan Elde Edilen Öntest ve Sontest Başarı Puanlarının Wilcoxon İşaretli Sıralar Testi Sonuçları

\begin{tabular}{lccccc}
\hline Sontest - Öntest & $\mathrm{n}$ & Sıra Ortalamas1 & Sira Toplam1 & $\mathrm{z}$ & $\mathrm{p}$ \\
\hline Negatif Sıra & 3 & 6.83 & 20.50 & $2,02^{*}$ & $.04^{* *}$ \\
Pozitif Sıra & 11 & 7.68 & 84.50 & & \\
Eşit & 4 & - & - & & \\
\hline
\end{tabular}

*Negatif siralar temeline dayalı, $* * \mathrm{p}<.05$

Tablo 6 incelendiğinde kontrol grubunda yer alan katılımcıların uygulama öncesi ve sonrasinda elde ettikleri puanların sıra ortalaması ve toplamı arasında anlamlı farklı olduğu görülmektedir $(\mathrm{z}=2.02, \mathrm{p}<.05) . \mathrm{Bu}$ durum programın öngördüğg̈ şekilde gerçekleştirilen eğitimin de akademik başarıyı etkilediği şeklinde yorumlanabilir. 
Uygulanan testler sonucunda her iki grubunda uygulanan süreç öncesi ve sonrası başarı puanları arasında anlamlı farklılıkların olduğu tespit edilmiştir. Ancak her iki grubun da anlamlılık değerleri incelendiğinde akademik başarıdaki artışın deney grubunda daha yüksek olduğu görülmektedir.

Araştırma kapsamında başarı testine ek olarak deney grubunda yer alan öğrencilerden seçilen bir grup öğrenciyle görüşme yapılmıştır. Bu bağlamda "Elektronik Yüzyll" ünitesinin işleniş sürecini değerlendirmeleri istenmiş ve Şekil 5 'teki bulgulara ulaşıılmıştır.

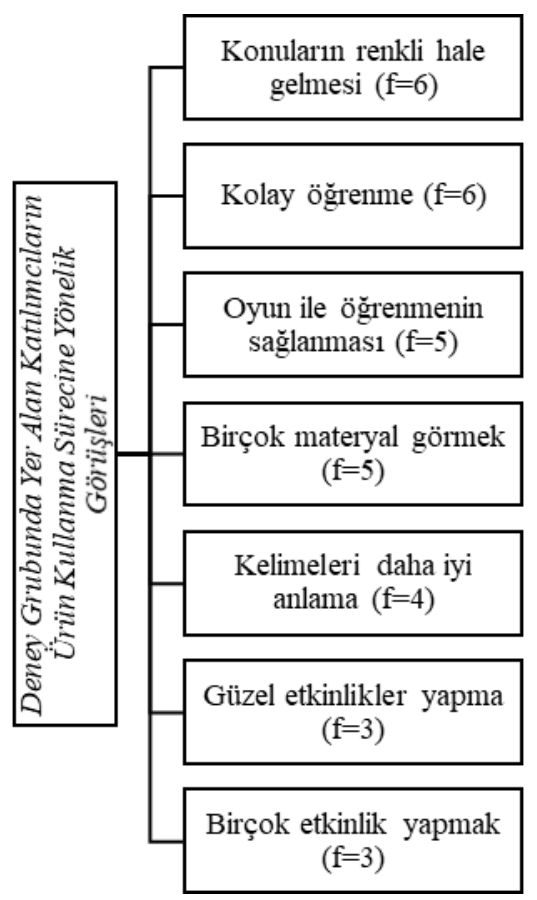

Şekil 5: Katılımcıların Süreç Değerlendirmelerine İlişkin Bulgular

Deney grubunda yer alan öğrencilere ünite kapsamında kullanılan ürünlerin dersi nasıl etkilediğine yönelik olarak gerçekleştirilen görüşme sonucunda derste kullanılan ürünlerin konuların renkli hâle gelmesini sağladığına $(\mathrm{f}=6)$, kolay öğrenmeye olanak tanıdığına ( $\mathrm{f}=6$ ), oyun ile öğrenmeyi sağladığına ( $\mathrm{f}=5$ ), birçok materyal görme imkânı 
sunduğuna ( $\mathrm{f}=5$ ), kelimeleri iyi anlamaya katkı sağladığına ( $\mathrm{f}=4$ ) birçok etkinlik yapmaya olanak tanıdığına (f=3) ulaşılmıştır. Aşağıda bazı öğrenci görüşlerine yer verilmiştir.

"Bu ünitede tarihi konulardan ziyade haklarımı ve korsanla mücadele konuları ele alınd ve eğlenceli materyaller kullanildı. Kullanilan materyaller konuların iyi bir şekilde aklımızda kalmasını sağladı." (DGÖ-1)

"Sinıf içinde uygulanan etkinlikler ve kullanılan materyallerle dersin hareketli ve güzel geçmesine sebep oldu. Konular zevkli hâle geldi. Etkinlik çarkl sayesinde konuları oyun ile ögrrenmiş olduk”. (DGÖ-3)

"Çark, tırtıl, oyunlar, karikatür tasarlama, zaman çizelgesi gibi materyaller kullanıldl. Özellikle sözlük iyiydi. Hepsi iyiydi. Sözlükten bilmediğim kelimeleri ögrrendim. Ĕ̆lenceli geldi, etkinlikler çok güzeldi.” (DGÖ-6)

"Bence kullanılan materyaller ve etkinlikler konuyu iyi bir şekilde anlamamızı sağladı. Eğlenceli ve öğretici olduğu için hepimiz çok sevdik ve eğlendik. Derste sözlük kullanımı ise çok işimize yaradı ve yeni kelimeler ögrendik.” (DGÖ-7)

Öğrenci görüşleri incelendiğinde derslerde farklı içeriklerin kullanılmasının, derse olan ilgiyi arttırarak, süreci eğlenceli hale getirdiği, konuların daha kalıcı öğrenilmesini sağladığı görülmektedir.

\section{SONUÇ, TARTIŞMA ve ÖNERİLER}

Araştırma kapsamında tasarım odaklı düşünme yaklaşımı aracılı̆̆ıyla sosyal bilgiler öğretiminde yaşanan problemler ve ihtiyaçlar belirlenerek, bunları gidermek amacıyla ürünler tasarlanmıştır. "Elektronik Yüzyıl ünitesine yönelik olarak tasarlanan bu ürünler okullarda uygulanmış, ürünlere yönelik uzman ve öğretmen geri bildirimleri alınmış ve test edilmiştir. Deneysel süreçte ürünlerin etkisinin net bir şekilde ortaya çıkarılması için oluşturulan deney ve kontrol gruplarının uygulama öncesinde "Elektronik Yüzyll" ünitesine yönelik başarı puanları karşılaştırılmıştır. Karşılaştırma sonucunda ise 
oluşturulan her iki grubun da "Elektronik Yüzyıl” ünitesine yönelik başarıları arasında istatistiki olarak anlamlı fark olmadığı belirlenmiştir. Başka bir ifadeyle katılımcıların “Elektronik Yüzyıl” ünitesine yönelik ön bilgileri birbirine yakındır.

Test aşamasında deney grubunda "Elektronik Yüzyıl” ünitesi öğretim sürecinde kullanılan ürünlerin akademik başarı üzerindeki etkisini ortaya çıkarmak amacıyla deney ve kontrol grubunun son test puanları analiz edilmiş ve deney grubunun lehine anlamlı sonuç tespit edilmiştir. Araştırma kapsamında deney grubuna uygulanan tasarım odaklı düşünme aracılığıyla geliştirilen ürünlerle öğretimin akademik başarıyı programın ön gördüğü şekilde gerçekleştirilen öğretime göre daha fazla arttırdığı tespit edilmiştir. Birtakım çalışmalarda da çeşitli sınıf düzeylerinde benzer şekilde, sosyal bilgiler dersinde farklı konuların işlenişinde materyal kullanımının akademik başarıyı olumlu yönde etkilediğine ulaşılmıştır (Akgül, 2019; Avşar, 2010; Kaymakçı, 2010; Kenger-Taşdemir, 2002; Kıy-Can, 2009; Namal, 2011; Sönmez, 2006; Yeşiltaş, 2006).

Araștırma kapsamında hem deney hem de kontrol grubunun öntest ve sontest puanları karşılaştırmalı olarak analiz edilmiştir. Hem deney hem de kontrol grubunun "Elektronik Yüzyıl” ünitesi öğretimi sonrasında elde ettikleri başarı puanlarının, öğretim öncesindeki puanlarla istatistiki olarak anlamlı bir şekilde farklılaştığı sonucuna ulaşılmıştır. Bir başka ifadeyle her iki grupta gerçekleştirilen öğretim katılımcıların akademik başarısını olumlu etkilemiştir. Ancak her iki grubun anlamlılık değerleri incelendiğinde deney grubunda yer alan katılımcılar da anlamlılık değerinin daha fazla olduğu görülmektedir. Bu durum da tasarım odaklı düşünme yaklaşımı aracılığıyla oluşturulan ürünlerle gerçekleştirilen öğretimin, programın ön gördüğü öğretime göre daha etkili olduğu ve akademik başarıyı daha fazla arttırdığı çeklinde ifade edilebilir.

Eğitim-öğretim ortamlarında amaca uygun ve etkili bir şekilde kullanılan araç-gereçler sürece önemli katkılar sağlamaktadır. Araç-gereçler amaca uygun ve etkili kullanıldığında, karmaşık bilgileri basite indirgeme, zamandan tasarruf etme, öğretimi canlı ve açık hâle getirme, işlem ve süreçlerin sırasını gösterme, bilginin gözde canlanmasını sağlama, öğrencinin ilgi ve dikkatini arttırma, soyut içerikleri somutlaştırma, hatırlamayı arttırma, öğrenilecek konu üzerinde pratik yapma imkânı ve 
çoklu öğrenme ortamı sağlama gibi faydalar sağlamaktadır (Çapar, 2012, s.24-25). Tasarım odaklı düşünme aracılığıyla geliştirilen ürünlerle gerçekleştirilen öğretim sürecinde yer alan öğrencilerle görüsşmeler yapılmış ve bu görüş̧meler sonucunda katılımcıların derste kullanılan ürünlerin kolay ve oyun ile öğrenmeyi sağladığı, birçok etkinlik yapmaya olanak tanıdığı, birçok materyali görme imkânı sunduğu ve dersin daha eğlenceli geçmesini sağladı̆̆ı gibi görüşlere sahip olduklarına ulaşılmıştır. Katılımcılar süreci faydalı özellikleriyle ele almışlardır. TC İnkılap Tarihi ve Atatürkçülük dersinde görsel materyal kullanımı sürecine ilişkin öğrenci görüşlerini inceleyen Düzenli (2019) de araştırma sonucunda katılımcıların süreci, görsel materyallerin dersi keyifli hale getirmesi, görsel materyallerin konunun daha iyi anlaşılmasına katkıda bulunması, görsel materyallerin konuları kolaylaştırması şeklinde değerlendirdiklerine ulaşmıştır.

Araştırma kapsamında elde edilen deneyimler sonucunda araştırmacılar ve uygulayıcılara yönelik olarak aşağıdaki öneriler geliştirilmiştir.

- Farklı alanların (Fen ve Teknoloji, Türkçe, Tarih, Coğrafya, Matematik...) öğretiminde yaşanan sorun veya ihtiyaçlara yönelik tasarım odaklı düşünme yaklaşımı aracıllğıyla ürün, içerik veya süreçler tasarlanabilir.

- Tasarım odaklı düşünme sürecinde test aşamasında görüş ve akademik başarının yanı sıra tutum, motivasyon gibi değişkenler de incelenebilir. 


\section{KAYNAKLAR}

Akgül, S. (2019). Illkokul sosyal bilgiler dersinde “insanlar ve yönetim” ünitesinin görsel materyal kullanılarak işlenmesi. (Yayımlanmamış yüksek lisans tezi). Ege Üniversitesi Sosyal Bilimler Enstitüsü, İzmir.

Altun, C. (2019). Sosyal bilgiler ögretmen adaylarının topluma hizmet uygulamalart projelerine tasarım odaklı düşünme becerilerini yansıtma süreçlerinin incelenmesi. (Yayımlanmamış yüksek lisans tezi). Ağrı İbrahim Çeçen Üniversitesi Sosyal Bilimler Enstitüsü, Ağrı.

Araújo, R., Anjos, E., \& Silva, R. (2015). Trends in the use design thinking for embedded systems. 15th International Conference on Computational Science and Applications (ICCSA), 82-86, Banff.

Atacan, B. (2020). 7.Sinıffen bilgisi dersinde tasarım odaklı düşünmeye yönelik etkinliğin öğrencilerin, motivasyon, ekip çalışması ve derse ilişkin baklş açılarına etkisi. (Yayımlanmamış yüksek lisans tezi). Balıkesir Üniversitesi Fen Bilimleri Enstitüsü, Balıkesir.

Avşar, S. (2012). Illköğretim ikinci kademe sosyal bilgiler derslerinde coğrafya konularının öğretiminde materyal kullanımının öğrenci başarısına etkisi. (Yayımlanmamış yüksek lisans tezi). Selçuk Üniversitesi Eğitim Bilimleri Enstitüsü, Konya.

Bakeman, R. \& Gottman, J. M. (1997). Observing interaction: introduction to sequential analysis (2. Edition). Cambridge: Cambridge University Press.

Ballia, J. (2019). Design thinking for progress. Initial insights from an evolving designled business support programme for Scotland. The Design Journal, 22(1), 981995.

Beckman, S. \& Barry, M. (2007). Innovation as a learning process: Embedded design thinking. California Management Review 50(1), 25-56.

Brown, T. \& Wyatt, J. (2010). Design thinking for social innovation. Stanford Social Innovation Review. Winter, 31-35.

Carlgren, L. (2013) Design thinking as an enabler of innovation: Exploring the concept and its relation to building innovation capabilities. ( $\mathrm{PhD}$ Thesis). Chalmers University of Technology, Gothenburg.

Creswell, J. W. (2017). Karma yöntem araştırmalarına giriş (3.Baskı). M. Sözbilir (Çev. Ed.), Ankara: Pegem.

Croll, P. (1986). Systematic classroom observation. London: The Farmer Press.

Chin, D.B., Blair, K.P., Wolf, R.C., Conlin, L.D., Cutumisu, M., Pfaffman, J., \& Schwartz, D.L. (2019) Educating and measuring choice: a test of the transfer of design thinking in problem solving and learning. Journal of the Learning Sciences, 28(3), 337-380. 
Çapar, D. (2019). Coğrafya öğretmenlerinin etkili materyal kullanımının öğrencilerin tutum, akademik başarı ve hatırda tutma düzeylerine etkisi (İzmir Örneği). (Yayımlanmamış doktora tezi). Dokuz Eylül Üniversitesi Eğitim Bilimleri Enstitüsü, İzmir.

Çetin, T. \& Aydemir, A. (2018). Sosyal bilgiler öğretiminde tasarım etkinliklerinin öğretmen görüşlerine göre incelenmesi: Elektronik yüzyıl ünitesi örneği. Turkish Studies Educational Sciences, 13(11), 445-466.

Dunne, D. \& Martin, R. (2006). Design thinking and how it will change management education. Academy of Management Learning and Education, 5(4), 512-523.

Düzenli, H. (2019). İlköğretim 8.sınıf T.C. inkılap tarihi ve atatürkçülük dersinde görsel materyal kullanımının ögrenci başarısına etkisi. (Yayımlanmamış yüksek lisans tezi). Manisa Celal Bayar Üniversitesi Sosyal Bilimler Enstitüsü, Manisa.

Gibbons, S. (2016). Design thinking 101. (https://www.nngroup.com/articles/designthinking/ sayfasından 10.06.2018 tarihinde erişilmiştir.

Girgin, D. (2019). Öğretmenlerin tasarım odaklı düşünmeye ilişkin bilişsel yapıları ve kavramsal değişimleri. Ahi Evran Üniversitesi Sosyal Bilimler Enstitüsü Dergisi, 5(2), 459-482.

Girgin, D. (2020). 21.yüyılın öğrenme deneyimi: öğretmenlerin tasarım odaklı düşünme eğitimine yönelik görüşleri. Milli Eğitim Dergisi, 49(226), 53-91.

Ingle, B. R. (2013). Design thinking for entrepreneurs and small businesses: putting the power of design to work. Berkeley, CA: A press.

Kayalı, D. (2019). Dijital öyküleme yöntemi aracılı̆̆ılla 6.sınıf ögrencilerinin tasarım odaklı düşünme becerilerinin geliştirilmesine yönelik bir eylem araştırması. (Yayımlanmamış yüksek lisans tezi). Muğla Sıtkı Koçman Üniversitesi Eğitim Bilimleri Enstitüsü, Muğla.

Kaymakçı, S. (2010). Sosyal bilgiler öğretiminde çalışma yaprakları kullanımının ögrencilerin akademik başarılarına ve derse karşı tutumlarına etkisi. (Yayımlanmamış doktora tezi). Gazi Üniversitesi Eğitim Bilimleri Enstitüsü, Ankara.

Kendir Çopurlar, C. \& Kılıç Öztürk, Y. (2015). Giotto hareketi 2. Ulusal kongresi tasarım odaklı düşünme çalıştayı izlenimleri. Türk Aile Hekimliği Dergisi, 19(1), 6-8.

Kenger Taşdemir, G. (2002) İlköğretim beşinci sınıf sosyal bilgiler dersinde hazır eğitim-öğretim araç-gereçleri ve öğretmen-öğrenci iş birliği ile hazırlanan araç-gereçlerle yapılan ögrenme etkinliklerinin akademik başarı ve kalıcılı̆̆a etkisi. (Yayımlanmamış yüksek lisans tezi). Çukurova Üniversitesi Sosyal Bilimler Enstitüsü, Adana. 
Kıy Can, S. (2009). İlköğretim 4. ve 5. Sınıflarda sosyal bilgiler dersinde (araç-gereç) materyal kullanımının öğrenci başarısına etkisi (Kars ili örneği). (Yayımlanmamış yüksek lisans tezi). Kafkas Üniversitesi Sosyal Bilimler Enstitüsü, Kars.

Knight, J., Fitton, D., Phillips, C., \& Price, D. (2019) Design thinking for innovation. stress testing human factors in ideation sessions. The Design Journal, 22(1), 1929-1939.

Li, R., Qian, Z.C., Chen, Y.V., \& Zhang, L. (2019). Design thinking driven interdisciplinary entrepreneurship. a case study of college students business plan competition. The Design Journal, 22 (1), 99-110.

Meinel, C. \& Leifer, L. (2010). Design Thinking Research. In H. Plattner, C. Meinel \& L. Leifer (Eds.), Design thinking understand-improve-apply (pp. xiii-xxi). Berlin: Springer Publishing Company.

Milli Eğitim Bakanlığı. (2005). Sosyal bilgiler 6.-7.sınıf programı. Ankara: Devlet Kitapları Müdürlüğü Basımevi.

Morris, H. \& Warman, G. (2015). Using design thinking in higher education. Educause Review.https://er.educause.edu/articles/2015/1/using-design-thinking-inhigher-education adresinden 06.06.2018 tarihinde erişilmiştir.

Namal, R. (2011). Illkögretim 7. sınıf sosyal bilgiler dersinde yer alan "ülkemizde nüfus" ünitesinin ögrretiminde görsel materyallerden yararlanmanın ögrenci başarısı üzerine etkisi. (Yayımlanmamış yüksek lisans tezi). Atatürk Üniversitesi Eğitim Bilimleri Enstitüsü, Erzurum.

Özçelik, D. A. (2010). Test hazırlama kılavuzu (4.baskl). Ankara: Pegem.

Öztürk, A. (2020). Tasarım odaklı düşünme yaklaşımı ile beşinci sınıflar için ortaklaşa stem etkinlikleri geliştirme. (Yayımlanmamış doktora tezi). Orta Doğu Teknik Üniversitesi Fen Bilimleri Enstitüsü, Ankara.

Robson, C. (1994). Real world research. Oxford: Blackwell Publishers Ltd.

Sarıbaş, S. \& Babadağ, G. (2015). Temel eğitimin temel sorunları. Anadolu Eğitim Liderliği ve Ö̆rretim Dergisi, 3(1), 18-34.

Sönmez, Ö. F. (2006). İlköğretim sosyal bilgiler 7.sınıf Karadeniz bölgesi konusunun görsel araç-gereçlerle ögretiminin ögrencilerin akademik başarısına etkisinin değerlendirilmesi (Tokat örneği). (Yayımlanmamış yüksek lisans tezi). Gazi Üniversitesi Eğitim Bilimleri Enstitüsü, Ankara.

Şahin, E. (2019). Tasarım odaklı düşünme yönteminin benlik saygısı ve yaratıcılık ile bilişsel ve duygusal bağlamda ilişkilendirilmesi: bir etkinlik çalışması. (Yayımlanmamış Yüksek Lisans Tezi). TOBB Ekonomi ve Teknoloji Üniversitesi Sosyal Bilimler Enstitüsü, Ankara. 
Thoring, K. \& Müller, R. M. (2011). Understanding the creative mechanisms of design thinking: an evolutionary approach. DESIRE'11-Creativy and Innovation in Design,Eindhoven: ACM Press.

TRT Haber (2019). MEB'den ögretmenlere tasarım odaklı düşünme eğitimi (İnternet Haberi). https://www.trthaber.com/haber/egitim/mebden-ogretmenleretasarim-odakli- dusunme-egitimi-427607.html adresinden 10. 09. 2020 tarihinde erişilmiştir.

Türnüklü, A. (2000). Eğitim bilim araştırmalarında etkin olarak kullanılabilecek nitel bir araştırma tekniği: görüşme. Kuram ve Uygulamada Eğitim Yönetimi, 24, 543-559.

Yeşiltaş, E. (2006). Sosyal bilgiler fiziki coğrafya konuları öğretiminde araç-gerę̧ kullanımının öğrencilerin başarı düzeylerine etkisi (Kars ili örneği). (Yayımlanmamış yüksek lisans tezi). Kafkas Üniversitesi Sosyal Bilimler Enstitüsü, Kars.

\section{ORCID}

Arcan Aydemir (iD https://orcid.org/0000-0001-8110-954X

Turhan Çetin (iD) https://orcid.org/0000-0002-2229-5255 


\section{SUMMARY}

Design thinking is defined as a design method that combines products, services, structures, space, experience, and the complex systems of products created by designers (Li, Qian, Chen, \& Zhang, 2019). Although design thinking is usually used by designers, it has recently been used by many people in various fields (Business education, educational sciences, etc.).

This study focused on the effectiveness of products developed in the design thinking process and aimed to investigate the effect of the products used on academic achievement and discover student views on the process using both qualitative and quantitative methods. Sequential descriptive (Quantitative $\rightarrow$ qualitative) design, one of the mixed research designs, was used in the study. In this context, firstly, quantitative method was applied and quantitative data were collected, then qualitative data were collected. The study used a quasi-experimental and control groups design in the quantitative phase and phenomenology in the qualitative phase. To better understand the impact of the products, two groups were selected with no significant difference between the scores on the achievement test developed for the "Electronic Century" Unit. Accordingly, the experimental group was taught using the products developed using the design thinking approach, while the control group was taught as the social studies curriculum sets out. The achievement test was administered to both groups before and after the process. In the process, both groups were taught by the current social studies teacher. In the qualitative phase of the study, interviews were held with seven randomly selected students in the experimental group to explore their views on the process. The products used in the teaching of the experimental group were created in the design thinking process performed with preservice social studies teachers. The sample consisted of 37 sixth-grade students attending a middle school in the Central District of the Artvin Province. The data were collected using the "Electronic Century" Achievement Test developed by the researcher and a semi-structured interview form. The quantitative data were analysed using the non-parametric Mann-Whitney $U$ test and the Wilcoxon signed-rank test to determine the effect of the experimental procedure because the number of participants was less than 30 in both groups. Statistical analysis was performed using SPSS software.

No significant difference was found between two groups in their scores on the "Electronic Century" Achievement Test. Thus, one group (experimental group) was taught using the products created through the design thinking approach. The other group (control group) was taught as the social studies curriculum sets out. The pretest and posttest scores were analysed. In line with the design thinking approach, the problems and needs of social studies teaching were identified and products were designed to address these problems and needs. No statistically significant difference was found between the groups. In other words, the participants' existing knowledge of the "Electronic Century" Unit was similar. The posttest achievement scores of the experimental and control groups were compared to explore the effect of the products used in the teaching of the "Electronic Century" Unit on academic achievement. A significant difference was found in favour of the experimental group. The pretest and posttest scores of both experimental and control groups were analysed comparatively. The posttest achievement scores of both groups differed statistically significantly from the pretest achievement scores. In other words, the teaching carried out in both groups had a positive effect on the academic achievement of the participants. However, when the 
significance values of both groups were considered, the significance value of the experimental group was higher. It can thus be said that the teaching carried out with the products created through the design thinking approach was more effective and led to a greater increase in academic achievement compared to the curriculum-based teaching. According to the analysis of the interview data, the participants held the view that the products used in the course facilitated learning, made the course more fun and allowed them to learn by playing and see various materials. The participants emphasised the useful features of the process. 
Ek-1 Etik Kurul Onayı

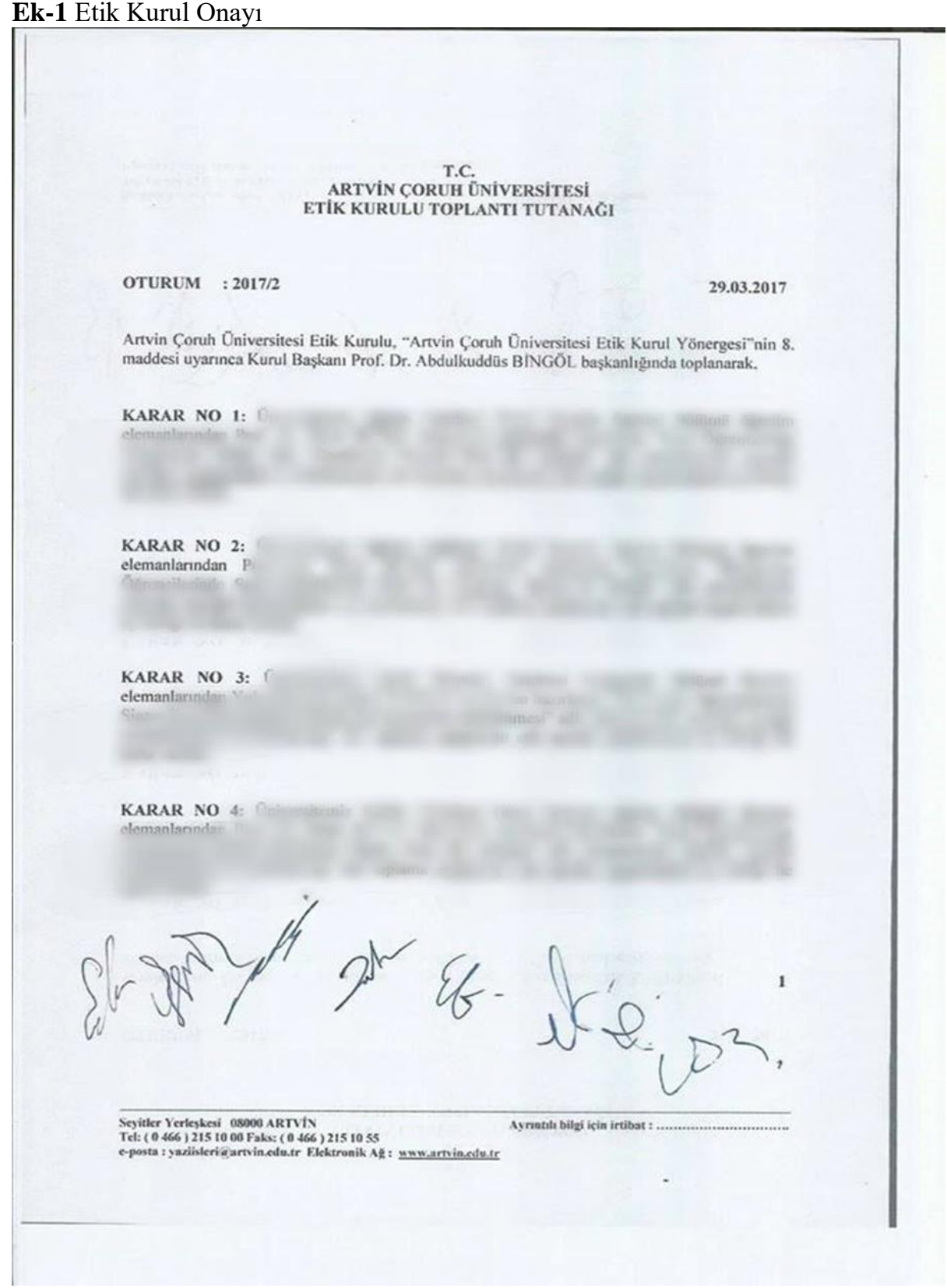




\section{KARAR}

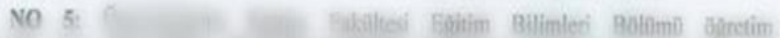
KARAR NO 6: Oniversitemiz Eğitim Fakültesi Türkçe ve Sosyal Bilimler Eg̈itimi Bölümū Eģitiminde Tasarım Odaklı Düsünme Yaklaşım" konulu doktora tezinde yapmak istedig̨i uygulamaların ve kullanacag̊ı veri toplama araçlannın etik açıdan uygunluğuna oy birliği ile karar verildi.

KARAR NO 7: On

Ginetim clemenlanndan

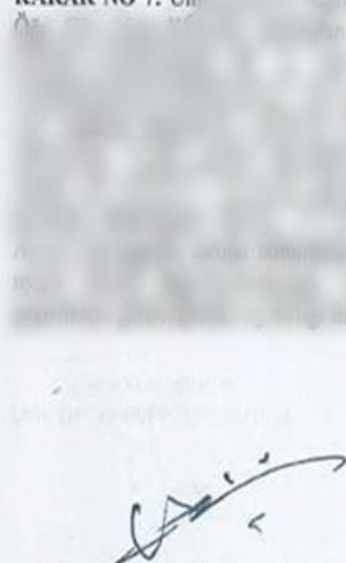

Prof. Dr. Abodulkuddäs BiNGỗ

Etik Kurul Başkant
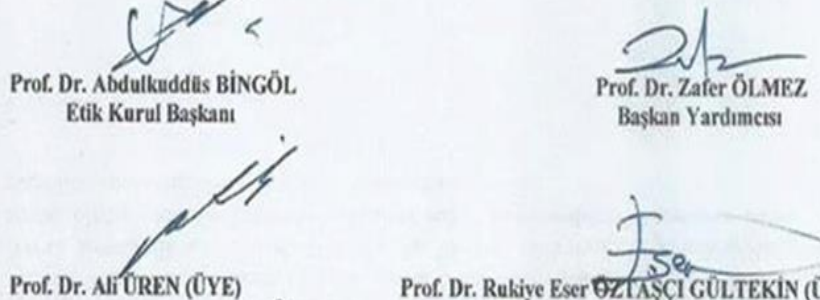

Prof. Dr. AITREN (OYE)

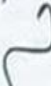

Baskan Yardımeısı

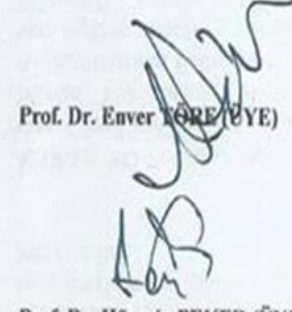

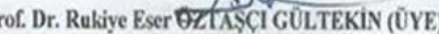

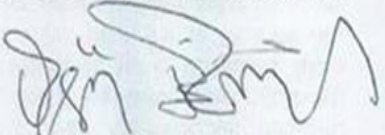

Prof. Dr. Õgür EMiNaĞaOĞLU (ÛYYE)

Prof. Dr. Hutseyin PEKER (ÛYE)

Av. Emite AGARTRAPORTO็R
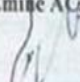

Seyitier Yerlegkesi 05000 ARTVis

Aynathi bilgi icin irtibat :

Tet: ( 0 \$66) 2151000 Faks: $(0466) 215105$

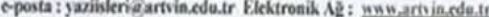

